separated from the hoy, or the, perhaps, more heavily-built drommelaar or drumbler; both of which we also borrowed, name and all, from the Hollander.

The names of the cromster and the drumbler survived in Holland at least as late as the end of the seventeenth century, Kromstevens were then the same as rond schuiten and drommelaars were of a different build; but both were probably different enough from their namesakes of a century earlier, although less strangely changed from their originals than were the kraaken and kaagen, that we find enumerated along with them, from the carracks and the cogs of still earlier days.

\title{
AN EARLY NAVAL CHEST.
}

By L. G. Carr Laughton.

THE chest represented in the accompanying photographs is in the possession of Messrs. Crichton Bros., of Old Bond Street.

It is an extremely handsome piece of furniture, made of soft wood with a domed lid, covered with unstained leather, heavily ornamented with brass furniture, and studded with patterns of brass nails on the front and top. From a naval point of view its most interesting feature is the badge, showing the foul anchor and crossed keys, which occurs three times on the chest itself, viz., once on the lid and twice on the front. These badges are brass castings in high relief.

Little or nothing is known of the history of the chest. Its present owners acquired it from a family which had, apparently, 
no connection with the Navy or with its administrative service ; and it had been in that family for generations.

The attempt to date and explain it must therefore be made chiefly from internal evidence, from the nature of the design, workmanship, and ornamentation, and from the badge itself. But, fortunately, very shortly after acquiring this chest, Messrs. Crichton were able to purchase another chest, in most respects an exact replica of it, at the late Earl of Home's sale. The second chest is the same size and shape as the original chest, of the same construction, and ornamented in the same way with brass furniture and patterns in brass-headed nails. The only essential difference is that the second chest has not the badges of the foul anchor and crossed keys, the space thereby occupied in the original chest being filled in the latter by patterns in brassheaded nails. The large badge on the lid of the first chest is replaced in the second by a nailed copy of the Stuart crown.

The early history of the second chest is equally obscure, but attached to a key to the chest-a key of comparatively modern make - is a label bearing the MS. inscription, on a leather tag, " Key, Chancellor of Exchequer Box, from Bothwell Castle (erased), Bruton Street (substituted), I8I8."

The original chest is in size $49 \frac{1}{2}$ ins. long by $27 \frac{1}{2}$ ins. wide by 27 ins. high to the top of the domed lid at the side. The second chest was not measured, but is apparently of the same size. Both have brass corner clasps, ending in a Stuart crown, and both have a large brass scutcheon lock plate of the same design. In each case this brass furniture is engraved, the designs being different. Each chest stands on a Chippendale stand, that of the original chest being an early example of his work bearing at the centre of its front side a reproduction of the anchor and keys badge, while the stand of the second chest is lower and has no badge.

The brass nails are arranged in conventional patterns, of which, in each case, the most noticeable is a tulip extending from each of the corners of the lid towards the centre.

The question is, What was the purpose, and who the owner, of what is described as the original chest? Its anchor badge seems to suggest a connection with the Admiralty. The keys seem to imply the ownership of the Treasurer of the Navy. And the existence of a later seal, believed to be of the time of the Great French Wars and belonging to the Office of the Treasurer of the Navy, also showing the foul anchor and keys, albeit arranged differently, tends to strengthen this belief. It is also 


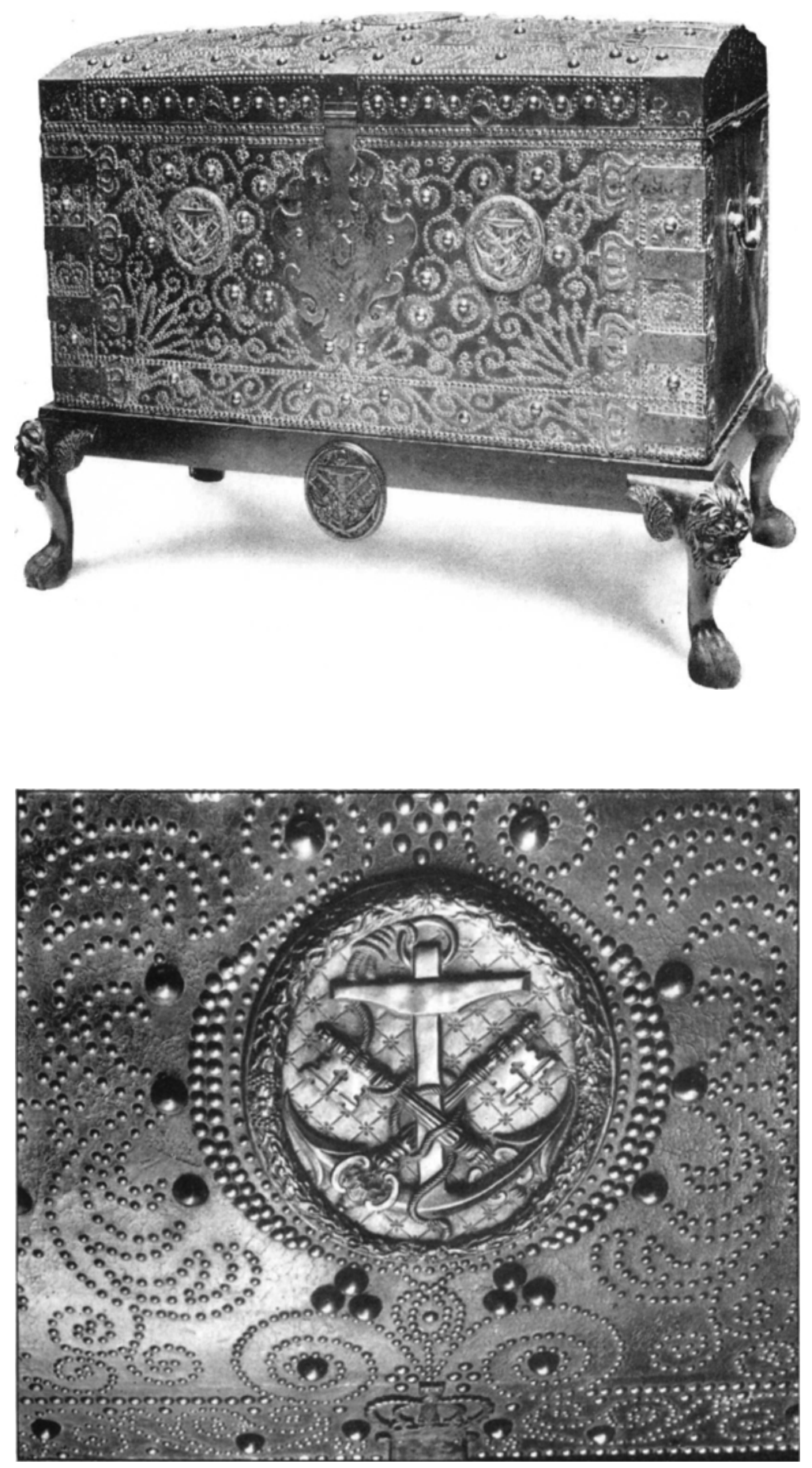
not to be neglected that comparatively early tradition ascribes the second chest to the Chancellor of the Exchequer. It is unfortunate that hitherto no one appears to have noted what was the seal of the Treasurer of the Navy, so that the adscription of the foul anchor and keys to his office is as yet merely a matter of conjecture, though, it would seem, a probable one.

Can any member add anything which would help to identify the original owner of this chest? Or give any definite information concerning either of the foul anchor and keys designs reproduced herewith? At present it is only possible to conjecture that this extremely handsome chest was a muniment box attached to the office of the Treasurer of the Navy, and that it was probably made roughly in the period $1670-1680$. But the pattern of foul anchor shown in the badges on the chest is not otherwise known for that, or for any other, date.

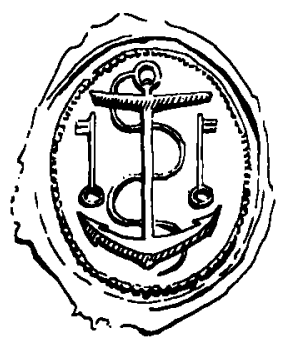

\section{EDWIN WILLIAMS.}

\section{BY ALAN MOORE.}

IT was with great regret, that some months ago, I found the Navy List no longer included the name of Lieut. Edwin E. Williams. The cover of the July MARINER's MIRror confirms his death.

Perhaps a few personal reminiscences by one who had the honour of his friendship for twenty years will be pardoned.

He was intimate with the late Samuel Evans, the Eton drawing 